\title{
RECREAÇÃO E PSICOLOGIA POSITIVA: CONSTRUINDO INTERFACES A PARTIR DE UM RELATO DE EXPERIÊNCIA
}

\author{
RECREACIÓN Y PSICOLOGÍA POSITIVA: CONSTRUYENDO INTERFACES A \\ PARTIR DE UN RELATO DE EXPERIENCIA
}

\author{
RECREATION AND POSITIVE PSYCHOLOGY: BUILDING INTERFACES FROM A \\ REPORT OF EXPERIENCE
}

\author{
Ivan FORTUNATO ${ }^{1}$
}

RESUMO: Este ensaio busca apresentar possíveis interfaces entre a recreação e a Psicologia Positiva, a partir da análise de um relato de experiência. Trata-se da análise das atividades desenvolvidas em um minicurso conduzido na ocasião do III Congresso Internacional de Psicologia do Esporte, Desenvolvimento Humano e Tecnologias, em setembro de 2017. Na oportunidade, um conjunto de jogos e brincadeiras foram utilizadas para apresentar uma possível relação entre a recreação e o olhar edificante da Psicologia Positiva. Ao final, esperase que as ideias embrionárias aqui apresentadas, que permitiram realizar proveitoso minicurso, sejam adensadas em novas oportunidades de praticá-las, ao mesmo tempo em que encorajem mais pesquisas que busquem relacionar a Psicologia Positiva com a recreação.

PALAVRAS-CHAVE: Brincadeira. Lazer. Recreação. Psicologia positiva.

RESUMEN: Este ensayo busca presentar posibles interfaces entre la recreación y la Psicología Positiva, a partir del análisis de un relato de experiencia. Se trata del análisis de las actividades desarrolladas en un minicurso conducido en ocasión del III Congreso Internacional de Psicología del Deporte, Desarrollo Humano y Tecnologías, en septiembre de 2017. En la oportunidad, un conjunto de bromas y juegos fueron utilizados para presentar una posible relación entre la recreación y la mirada edificante de la Psicología Positiva. Al final, se espera que las ideas embrionarias aquí presentadas, que permitieron realizar provechosos minicurso, sean adensadas en nuevas oportunidades de practicarlas, al mismo tiempo que alienten más investigaciones que busquen relacionar la Psicología Positiva con la recreación.

PALABRAS CLAVE: Broma. Ocio. Recreación. Psicología positiva.

ABSTRACT: This essay seeks to present possible interfaces between recreation and Positive Psychology, based on the analysis of an experience report. This is the analysis of the activities developed in a mini-course conducted on the occasion of the III International Congress of Psychology of Sport, Human Development and Technologies, in September 2017.

1 Instituto Federal de São Paulo (IFSP), Itapetininga, SP, Brasil; Universidade Federal de São Carlos (UFSCar),Sorocaba - SP - Brasil. Coordenador da licenciatura em Formação Pedagógica/IFSP e professor permanente do PPGEd/UFSCar. ORCID: <http://orcid.org/0000-0002-1870-7528>. E-mail: ivanfrt@yahoo.com.br 
On the occasion, a set of games were used to present a possible relationship between the recreation and the edifying look of Positive Psychology. In the end, it is hoped that the embryonic ideas presented here, which have allowed us to make a useful mini-course, will be densified in new opportunities to practice them, while encouraging more research that seeks to relate Positive Psychology to recreation.

KEYWORDS: Playing. Leisure. Recreation. Positive Psychology.

Este artigo, escrito na forma de ensaio, busca apresentar possíveis interfaces entre a recreação e a Psicologia Positiva, a partir da análise de um relato de experiência. De forma embrionária, essa relação começou a ser elaborada durante as pesquisas realizadas no LEL (Laboratório de Estudos de Lazer) da UNESP de Rio Claro, no período de doutoramento em Desenvolvimento Humano e Tecnologias, entre 2015 e 2018. Nessa época, tomei a Psicologia Positiva como pedra fundamental para pensar a resiliência como um constructo psicológico potencialmente aprendido com e pelo cinema (FORTUNATO, 2018). Assim, tal fundamentação construída permitiu observar o lazer por uma ótica muito mais progressista, sendo compreendido além daquilo que se faz quando não se está trabalhando, ou, compreendido conforme Bramante (1998), isto é, como uma experiência pessoal. De maneira análoga, a recreação emergia na figura de um rol de atividades lúdicas de distração ou passatempos, a qual se tornava elemento efetivo de uma vida mais próspera, de bem-estar e felicidade.

O convite feito pelo laboratório parceiro, o LEPESPE (Laboratório de Estudos e Pesquisas em Psicologia do Esporte), para conduzir um minicurso no III Congresso Internacional de Psicologia do Esporte, Desenvolvimento Humano e Tecnologias, em setembro de 2017, apareceu como oportunidade ímpar para verificar a possibilidade de ensaiar algumas práticas de recreação ancoradas nos ideais da Psicologia Positiva. Como o público de um evento dessa natureza é, geralmente, formado por pesquisadores e/ou profissionais da área, o teste da recreação pela Psicologia Positiva passaria pelo crivo crítico de quem atua cotidianamente com lazer, educação física e áreas afins.

O minicurso deveria ocupar quatro horas no total, sendo desenvolvido em uma sala de aula equipada com computador, projetor, cadeiras tipo universitária e ar condicionado. Dispostas em fileiras, a sala poderia comportar mais de 40 participantes, mas para o minicurso foram disponibilizadas 20 vagas, sendo 17 efetivamente preenchidas. $\mathrm{O}$ título dado foi curto e pouco esclarecedor, pois, foram utilizadas apenas as palavras-chaves Recreação \& Psicologia 
Positiva. O objetivo era provocar algum tipo de curiosidade nos participantes, sensibilizandoos para a atividade.

Outra particularidade proposta no minicurso era evitar possíveis discussões a respeito do termo "recreação" e suas semelhanças e diferenças com o conceito de lazer. Sabe-se, como já apresentado por diversos autores, tais como Chaves, Gamboa e Sá (2003) e Moreno e Marcellino (2006), que lazer e recreação são conceitos caros à Educação Física, mas que se confundem no senso comum, tornando-se até sinônimos. Além disso, não há um consenso estabelecido na área sobre sua definição. Portanto, para evitar que as práticas propostas no minicurso pudessem ser eclipsadas por debates retóricos, foi estabelecido que a recreação seria entendida conforme Paçoca e Gonçalves (2017, p. 21), ou seja, um conjunto de atividades lúdicas "que os indivíduos fazem para satisfazer as necessidades físicas, psíquicas ou sociais".

Ao recepcionar os participantes, breve apresentação pessoal foi feita, buscando contextualizar a proposta. Dessa forma, foi recuperada a experiência com o desenvolvimento da tese a partir da Psicologia Positiva, qualificando essa linha de estudo como a busca por valores e forças de caráter nas experiências subjetivas, considerando o bem-estar, a felicidade, a satisfação, o otimismo e a esperança como elementos fundantes; exatamente conforme foi proposto em seu artigo inaugural, publicado por Seligman e Csikszentmihalyi (2000). O título do minicurso foi projetado e dividido em duas telas: (1) Recreação e (2) Psicologia Positiva, reservando a segunda para um momento oportuno, perto do encerramento. Assim, o prefácio foi ligeiro, pois o curso foi planejado para ser divertido.

A recreação foi organizada por um roteiro em três passos, sendo: (1) Aproximar \& Desinibir, (2) Rir \& Se Divertir, e (3) Comentar \& Lembrar. Cada um desses passos foi pensado com um objetivo singular, para que a recreação pudesse ser, ao mesmo tempo, curtição e lição. O primeiro passo foi inspirado em Paçoca e Araújo (2017, p. 23), que consideraram que "brincar é uma oportunidade de estar junto, e se está junto verdadeiramente, é muito importante ouvir o que o outro tem a dizer". Como o grupo do minicurso foi formado naquela sala de aula, a partir das inscrições realizadas pelo sítio eletrônico do evento, partiuse do pressuposto que as pessoas ali eram estranhas entre si. Mesmo havendo pequenos grupos de amigos que se inscreveram para participar, aquele coletivo de 17 pessoas era inédito. Dessa maneira, o primeiro passo foi visto como oportunidade de "estar junto", mas também de "ouvir" e "falar".

As divisas foram dadas: (a.) use alguma tecnologia digital (como celular) ou analógica (como papel e caneta) para anotações; (b.) circule, converse, brinque e encontre alguém que... 
e; (c) colete as dez (10) informações, mas cada item deve ser obtido de um colega distinto. Para completar as reticências da divisa "(b)", foram apresentadas uma dezena de comandos, listados no quadro reproduzido na Figura 01 a seguir, cada um com a intenção de permitir que os participantes pudessem se aproximar uns dos outros de uma maneira divertida, mas sem constrangimento. Isso porque cada tópico continha elementos pessoais, mas nada que invadisse a esfera do que é estritamente privado. Pelo contrário, tratavam de filmes, séries, viagens e assim por diante; ou seja, elementos lúdicos, sobre os quais, geralmente, as pessoas têm muito prazer em partilhar - mesmo que seja com recém conhecidos.

Figura 01: Comandos do primeiro passo da recreação: Aproximar \& Desinibir

\section{CIRCULE, CONVERSE, BRINQUE E ENCONTRE ALGUÉM QUE...}

1. Você não conhecia e vai se lembrar do nome, mesmo sem escrevê-lo

2. Tire uma selfie fazendo careta com você

3. Conte uma piada que lhe faça rir e que você seja capaz de contar ao grupo

4. Tenha habilidades artísticas que você consiga contar para o grupo

5. Tenha um hobby que você ache interessante

6. Assista a mesma série que você e que goste de um episódio que você gosta

7. Indique um filme cujos motivos façam você querer assistir

8. Fale de uma viagem que fez e que você vai querer fazer também

9. Tenha lido um livro que você nunca ouviu falar, mas que a história é bem legal e até dá vontade de ler, mesmo sabendo que você não vai ler

10. Conhece uma brincadeira que você não conhecia e que vale a pena experimentar hoje

Fonte: Acervo próprio

Nem bem foi dada a indicação que a atividade poderia começar, e todos os participantes já estavam de pé, modificando o cenário da sala de aula de cadeiras dispostas em colunas, para algo parecido com um círculo, sobre o qual se pudesse, de fato, circular. Em pouco tempo já estavam se movimentando, tirando selfies produzidas com as mais inusitadas caras e bocas, falando (alto) e rindo (muito alto). A dinâmica da atividade demonstrou que os objetivos de "aproximar" e de "desinibir" foram plenamente alcançados. Pois todos estavam envolvidos no jogo, partilhando suas habilidades e hobbies, conversando sobre filmes, seriados e livros, comentando sobre alguma viagem inesquecível, alguma brincadeira que gosta, e até contando piadas.

Tudo isso foi suficiente para preparar para a próxima atividade da recreação. Mas, antes, tomamos por base as dez divisas presentes no quadro da Figura 01, para ir compondo 
equipes para o próximo jogo. Assim, logo foi perguntado quem se lembrava do nome de algum colega que, até momentos antes da primeira brincadeira, era um desconhecido. A resposta veio rapidamente, e as pessoas começaram a dizer os nomes uns dos outros, relacionando os nomes e suas feições a diversas outras características que foram abordadas nos elementos do quadro. Aos poucos, com certa organização, foi possível ir passando, divisa por divisa, perguntando uma para cada participante, de maneira que aquele que lembrou o nome de alguém, se juntou a este na equipe. Na sequência, quem teve o nome lembrado, mostrou a selfie que mais gostou, e seu parceiro de foto se adentrou na equipe, e assim por diante. Seguindo essa dinâmica, buscando sempre manter o bom humor elevado na partilha das particularidades do outro, que foram descobertas no início de curso, três equipes foram formadas.

Concluído o primeiro passo da recreação proposta, foi dado seguimento para a etapa dois, nomeada "Rir \& Se Divertir". Conforme foi apontado por Carbelo e Jáuregui (2006, p. 21), o riso desempenha protagonismo na Psicologia Positiva, sendo "una emoción unitaria que reacciona directamente a estímulos externos, constituyendo en sí un juicio de valor ${ }^{2} "$. No entanto, os autores afirmam ser praticamente impossível gerar o riso genuíno na pesquisa laboratorial. Por isso, o riso foi programado para acontecer durante o minicurso, afinal, tratava-se de uma experiência controlada, portanto, uma espécie de laboratório, pois tudo seria analisado e refletido pela ótica da Psicologia Positiva.

Com a simples divisa "pensem positivo", foi projetada uma imagem com um rolo de papel higiênico ao centro, ladeado por cortinas de teatro, reproduzida a seguir na Figura 02. Certa comicidade era esperada ao posicionar o rolo como astro principal da cena, especialmente ao relacioná-lo com o mote de pensar positivo.

Figura 02: O motivador para o segundo passo da atividade recreativa, projetado sob a máxima "pensem positivo".

2 Tradução livre: $\mathrm{O}$ riso é uma emoção singular que reage diretamente aos estímulos externos, constituindo-se julgamento de valor. 


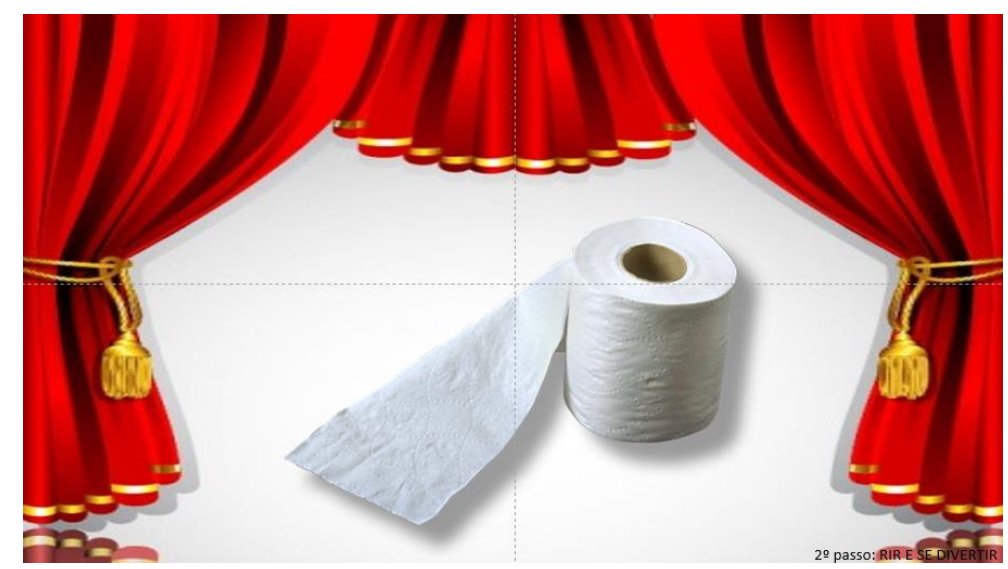

Fonte: Acervo próprio

Aos grupos ora formados, foi apresentado o seguinte desafio: criar uma apresentação na qual o protagonista - o papel higiênico, no caso - assumisse novo papel social. Ou seja, o papel higiênico não poderia ser usado para fins de higiene, mas deveria representar algo que fosse positivo para aquele grupo que acabava de se formar. Tratava-se de uma proposta de improvisação aliada ao jogo teatral, adaptada de Paçoca et al (2013), cujo objetivo, no minicurso, era somente o entretenimento, e a promoção da alegria e do riso.

O tempo disponibilizado para a elaboração da cena teatral foi, inicialmente, dez minutos. Durante esse período, foi sugerido que formulassem algo divertido, usando a criatividade para dar nova roupagem ao personagem principal. O tempo de dez minutos foi curto, pois, enquanto estavam engajados na atividade, os grupos foram praticamente unânimes em relatar que nem viram o tempo passar. Prorrogamos, então, em dez minutos o início das apresentações. Essa questão da percepção relativa do tempo pode ser qualificada como sendo algo do senso comum, sobre a qual as pessoas amiúde relatam sobre um minuto que levou uma eternidade, ou sobre horas que fluíram como se fossem minutos. Não obstante, isso foi identificado por Csikszentmihalyi (1999) como uma das características essenciais para o "estado de fluxo". Este estado pode ser definido como o momento em que se está fazendo algo com total comprometimento e vontade, como se essa atividade fosse o propósito da vida em si.

Nesse sentido, considerar que o tempo inicial foi escasso é uma possível evidência de que o desafio proposto para a elaboração de uma cena dramatizada, com foco na diversão e bom humor, possibilitou o acesso ao estado de fluxo. Obviamente, não existe a pretensão de afirmar que a condução de uma atividade é bastante para promover o fluxo, muito menos postular que essa atividade específica, planejada com objetivos didáticos para um minicurso, foi promotora de estados de fluxos diversos. Mesmo assim, é preciso considerar que, por 
mínima que tenha sido, a presença de uma evidência positiva foi algo substancialmente pertinente à busca de correlações entre a recreação e a Psicologia Positiva.

Parece plausível inferir, portanto, que houve, na organização da improvisação teatral motivada pelo rolo de papel higiênico, rudimentos de aspectos positivos, como um potencial acesso ao estado de fluxo. Esses indícios rudimentares apenas colaboram para certificar que os objetivos iniciais estavam sendo alcançados. E isso se tornou um pouco mais acentuado no momento de apresentação das cenas criadas a partir da divisa "rir \& se divertir". Cada grupo se apresentou em pouco mais de um minuto, tendo a participação de todos seus membros na execução da cena. $\mathrm{O}$ primeiro grupo transformou o rolo de papel higiênico em um pergaminho, e os outros dois grupos deram nomes ao rolo, personificando-os. A criatividade foi o meio escolhido para resolver o desafio de improvisar, colocar o objeto indicado como protagonista e, mais importante, focar na diversão.

Passadas as dramatizações e o momento divertido que elas proporcionaram, pudemos dar início à terceira e última etapa da recreação, nomeada como "comentar \& relembrar". Com base na teoria da dinâmica de grupos, a etapa da partilha foi qualificado por Fonseca Filho (1984) como um momento de comentar, discutir e analisar o que visto e sentido. Para esse autor, indicativos positivos a respeito da maturação e empatia de um grupo são diálogos espontâneos, francos e harmoniosos, sendo tais aspectos esperados emergir nesse momento do minicurso. Assim, no contexto, essa etapa foi planejada com o objetivo de identificar tais qualificadores no grupo, após uma tarde de atividades de recreação pautadas na Psicologia Positiva. Outro objetivo era poder destacar todos os aspectos positivos das atividades anteriores, por meio de uma roda de conversas. Obviamente, buscou-se ouvir potenciais comentários negativos, que poderiam ser críticas para melhoras ações futuras, contudo, o propósito maior seria o de manter o foco nas qualidades positivas do (e decorrente do) trabalho realizado.

Assim, foi perguntado coletivamente o que tinham percebido de relevante nas etapas anteriores, pedindo para que fosse cotejado o vivido com as expectativas criadas a partir da decisão de participar de um minicurso que trataria de recreação e Psicologia Positiva. Alguns participantes logo se manifestaram favoráveis às atividades recreativas daquela tarde, ratificando que os objetivos propostos, conforme foram declarados no início do minicurso, foram alcançados.

Retomamos a primeira atividade, que se desenvolveu de maneira bastante descontraída, compreendendo-a como um convite à aproximação amistosa entre os participantes. Poder falar sobre atividades, filmes e seriados, viagens, etc., foi bastante 
oportuno para aproximar as pessoas, indo além do costumeiro "quebra-gelo", mas efetivamente estabelecendo vínculos importantes para a fase seguintes. Comentou-se sobre os hobbies e habilidades que foram descobertos naquela atividade, trocou-se experiências sobre viagens e foram partilhados filmes e séries que já eram de gosto comum, tendo alguns ressaltado que, naquele grupo, tiveram excelentes recomendações de séries, filmes e livros. Todo diálogo estabelecido nessa etapa de "comentar \& relembrar" foi desenvolvido com elementos espontâneos, francos e harmoniosos, permitindo afirmar, conforme delineado anteriormente, que aquele grupo havia alcançado adequado estágio de amadurecimento e empatia, provavelmente tendo as emoções positivas das atividades como elo.

$\mathrm{Na}$ sequência, comentamos e relembramos as cenas que foram dramatizadas e o quanto foi divertido seu planejamento - que nem se viu o tempo passar - e o quanto foi agradável poder assistir as cenas. E eis uma interessante conjectura, lançada no momento do minicurso: é provável que o regalo sentido ao ver a execução das cenas planejadas pelos colegas tenha relação direta com o fato de se estar testemunhando pessoas genuinamente se divertindo. Isso faz sentido, especialmente se considerarmos que cada pequena passagem dramatizada foi elaborada, por cada grupo, com bastante entusiasmo e foco no objetivo divisado: rir e se divertir. Isso quer dizer que, provavelmente, as cenas que foram apresentadas no contexto do minicurso, não provocassem o riso de outra plateia, nem o júbilo de quem a estaria executando. Eis uma hipótese que pode nortear futuras pesquisas interessadas nessa relação entre a prática da recreação e a ótica otimista da Psicologia Positiva.

O surgimento dessa hipótese foi a ocasião oportuna para introduzir, no minicurso, elementos da teoria da Psicologia Positiva que serviram de aporte ao planejamento das atividades. Começamos com a ideia de fluxo, já delineadas aqui, e avançamos às ideias a respeito das emoções positivas de Fredrickson (2001). Essa autora foi responsável pela expressão "teoria broaden-and-build", a qual pode ser descrita como uma teoria que visa ampliar e construir a presença de emoções positivas no cotidiano. Dito de outra forma, a autora percebeu que existe um descompasso entre a quantidade e a qualidade de emoções positivas e negativas na vida das pessoas. Fredrickson (2001) argumenta que há cerca de quatro vezes mais descritores para emoções negativas que para emoções positivas. Além disso, notou que as emoções negativas são mais facilmente reconhecidas nos outros, por conta das expressões faciais e linguagem corporal. Isso quer dizer que enquanto facilmente se identifica raiva, tristeza ou dor em nossos interlocutores, existe grande dificuldade em 
decodificar uma emoção positiva como alegria, contentamento e felicidade, pois estas são estampadas no rosto e na linguagem corporal de formas muito semelhantes.

Com a teoria broaden-and-build, a Psicologia Positiva tem uma forte aliada para os estudos das emoções positivas, pois essas têm implicações igualmente positivas na qualidade de vida e no bem-estar. Uma das maneiras pensadas para expandir e construir emoções positivas foi o uso de atividades de recreação destinadas ao divertimento e ao riso. Para o fortalecimento das emoções positivas, não se recomenda atividades recreativas que envolvam competição, pois essas podem gerar ansiedade, raiva, tristeza e outras emoções negativas, contrariando a proposta de fortalecer as emoções positivas.

Depois dessas elucubrações sobre a teoria da Psicologia Positiva aliada às práticas recreativas, pudemos finalizar o minicurso. Para isso, foi pedido que cada um se manifestasse, de forma bastante sucinta, a respeito de possíveis aprendizados decorrentes da ação educativa. Todos os comentários produzidos foram praticamente unânimes ao destacar que as atividades recreativas foram conduzidas de forma a manter o bom-humor e aproximação fraterna entre os participantes. Esses apontamentos como desfecho, a intensa participação coletiva e o bomhumor durante todo o minicurso, são indícios de que a relação entre recreação e Psicologia Positiva vale a pena continuar a ser explorada.

\section{REFERÊNCIAS}

BRAMANTE, A. C. Lazer: concepções e significados. Licere, Belo Horizonte, v. 1, n. 1, p. 9-17, 1998.

CARBELO, B.; JÁUREGUI, E. Emociones positivas: humor positivo. Papeles del Psicólogo, Madrid, v. 27, n. 1, p. 18-30, 2006.

CSIKSZENTMIHALYI, M. A descoberta do fluxo: a psicologia do envolvimento com a vida cotidiana. Trad. Pedro Ribeiro. Rio de Janeiro: Rocco, 1999

CHAVES, M.; GAMBOA, S. S.; SÁ, K. O. de. Lazer e recreação no currículo de Educação Física. Maceió, EDUFAL, 2003.

FONSECA FILHO, J. Psicodrama: breve histórico; resumo da teoria e da técnica. In: MORENO, J. L.; ENNEIS, J. M. Hipnodrama e Psicodrama. São Paulo: Summus Editorial, 1984.

FORTUNATO, I. Quando a resiliência vai ao cinema: superação e felicidade pela ótica da Psicologia Positiva. Tese (doutorado em Desenvolvimento Humano). Rio Claro: Instituto de Biociências, Universidade Estadual Paulista, 2018. 
FREDRICKSON, B. L. The role of positive emotions in positive psychology: the broadenand-build theory of positive emotions. American Psychologist, Washington, v. 56, n. 3, p. 218-226, 2001.

MORENO, S. T. S.; MARCELLINO, N. C. Lazer/recreação e formação profissional. Licere, Belo Horizonte, v. 9, n. 1, p. 108-134, 2006.

PAÇOCA, T. A. da C. e S.; ARAÚJO, C. do S. Bora brincar: um convite à brincadeira. São Paulo: All Print Editora, 2017.

PAÇOCA, T. A. da C. e S.; GONÇALVES, K. G. F. Manual de lazer e recreação: o mundo lúdico ao alcance de todos. $2^{\mathrm{a}}$ ed. São Paulo: Phorte editora, 2017.

PAÇOCA, T. A. da C.; PINES JUNIOR, A. R.; SCHWARTZ, G. M.; GONCALVES, K. G. F.; LEÃO JUNIOR, C. M. Jogos de Improviso como estratégia para o bem estar na educação. Licere, Belo Horizonte, v. 16, p. 1-17, 2013.

SELIGMAN, M. E. P.; CSIKSZENTMIHALYI, M. Positive Psychology: an introduction. American Psychologist, Washington, v. 55, n. 1, p. 5-14, 2000.

\section{Como referenciar este artigo}

FORTUNATO, Ivan. Recreação e Psicologia Positiva: construindo interfaces a partir de um relato de experiência. Doxa: Rev. Bras. Psico. e Educ., Araraquara, v. 20, n. 1, p. 42-51, jan./jun., 2018. e-ISSN: 2594-8385. DOI: 10.30715/rbpe.v20.n1.2018.11253

Submetido em: 29/03/2018

Aprovado em: 18/05/2018 